\title{
Fighting the good cause: meaning, purpose, difference, and choice
}

\section{Citation}

Haig, David. 2014. "Fighting the Good Cause: Meaning, Purpose, Difference, and Choice." Biol Philos 29 (5) (February 18): 675-697. doi:10.1007/s10539-014-9432-4.

\section{Published Version}

doi:10.1007/s10539-014-9432-4

\section{Permanent link}

http://nrs.harvard.edu/urn-3:HUL.InstRepos:24981605

\section{Terms of Use}

This article was downloaded from Harvard University's DASH repository, and is made available under the terms and conditions applicable to Open Access Policy Articles, as set forth at http:// nrs.harvard.edu/urn-3:HUL.InstRepos:dash.current.terms-of-use\#OAP

\section{Share Your Story}

The Harvard community has made this article openly available.

Please share how this access benefits you. Submit a story.

\section{Accessibility}




\title{
Fighting the good cause:
}

\section{meaning, purpose, difference, and choice}

\author{
David Haig \\ Department of Organismic and Evolutionary Biology, \\ Harvard University, 26 Oxford Street, \\ Cambridge MA 02138.
}




\begin{abstract}
Concepts of cause, choice, and information are closely related. A cause is a choice that can be held responsible. It is a difference that makes a difference. Information about past causes and their effects is a valuable commodity because it can be used to guide future choices. Information about criteria of choice is generated by choosing a subset from an ensemble for 'reasons' and has meaning for an interpreter when it is used to achieve an end. Natural selection evolves interpreters with ends. Surviving genes embody a textual record of past choices that had favorable outcomes. Consultation of these archives guides current choices. Purposive choice is well-informed difference making.
\end{abstract}

Keywords: final causes; formal causes; information; teleology; recursion; selection; choice; difference; text; interpretation 
Many four-year-olds delight in asking "Why?" and when one offers an explanation, respond with another "Why?" requesting an explanation of the explanation, until explanatory exhaustion. Aristotle and Thomas Aquinas used the threatened infinite regress of causes of causes to demonstrate the existence of an unmoved mover, but a child recognizes the game could go on forever.

The central conceit of The life and opinions of Tristram Shandy, Gentleman (Sterne 1767) is that the novel sets out to recount the life of its hero but, to place him in context and to explain the causal influences on his character, the text wanders with digressions, and digressions on digressions, with a regress of causes and their causes so that, in the end, we learn little about the eponymous Tristram. A seminal event occurs at the moment of Tristram's conception when his mother asks his father "Pray, my Dear, have you not forgot to wind up the clock?" This question "scattered and dispersed the animal spirits, whose business it was to have escorted and gone hand in hand with the HOMUNCULUS, and conducted him safe to the place destined for his reception." From this minor, but far from inconsequential, perturbation followed many oddities of Tristram's character.

It is not implausible, indeed it is probable, that whatever my father and mother were thinking during the consummatory act before my conception had an influence on their posture and on which of the myriad sperm in my father's ejaculate won the race to the ovum in my mother's oviduct. 'Replaying the tape of life' retells a story in every detail because the sequence of causes remains unchanged. But the first time the tape was played, there was no way of knowing, until it happened, which of my father's sperm 
would fertilize my mother's egg. There is a single causal narrative out of the past but a beyond astronomical proliferation of possibilities into the future. One can explain with much greater confidence than one can predict.

Taking a step further back from my conception, a complex convergence of molecular events determined the location of chiasmata in the spermatocyte that gave rise to my haploid paternal progenitor. If any one of thirty-odd chiasmata had occurred a mere megabase to either side, then the child conceived would not have inherited my particular set of genes, and the same will have been true of the conception of every one of my ancestors. But a molecular explanation of the location of untold chiasmata would comprise only an infinitesimal part of what a complete causal account of my ancestry would entail. My father's father was an ambulance driver at the second battle of VillersBrettoneux. So, an account of his survival, where so many others died, would need to explain the trajectories of innumerable projectiles and their fragments, and so on to the endlessly disputed causes of the First World War.

The point of this reductio ad absurdum is that, while all evolutionary processes are, in principle, reducible to physical causes, no feasible account can be causally complete. Every story needs a place to begin which leaves many things unsaid. So too, all scientific explanations include items that, for present purposes, are accepted without explanation. 


\section{Aristotle redux}

"It were infinite for the law to judge the cause of causes, and their impulsions one of another; therefore it contenteth itself with the immediate cause, and judgeth of the acts by that, without looking to any further degree." (Bacon 1596)

In pre-classical Greek, aition and aitia had connotations of responsibility, guilt, blame, and accusation (Pearson 1952; Frede 1980). Aristotle's aitia was translated into classical Latin causa, a word that could refer to a lawsuit as in nemo iudex in causa sua. English cause was adopted from medieval Latin around 1300 and retains legal uses as in show cause. A similar association of cause and culpability occurs in Germanic languages. German Ursache (cause) is related to Anglo-Saxon sake as in for the sake of. Sake could refer to a lawsuit, complaint, accusation, or guilt. Thus, concepts of cause appear to have evolved from proto-legal notions of blameworthiness. A cause was something that could be held responsible.

Aristotle recognized four kinds of aitia; traditionally translated as material, efficient, formal, and final causes. Bacon (1605/1885) embraced material and efficient causes as the proper domain of physics but banished formal and final causes to the realm of metaphysics (p. 114). Aristotelian pluralism was supplanted by a monistic concept of causation of which efficient cause was the dynamical aspect and material cause the physical substrate. In the new mechanical philosophy, form lacked independent potency but was "confined and determined by matter" (p. 115). Final causes were disparaged as 
an encumbrance to the advancement of learning, as "remoraes and hindrances to stay and slug the ship from further sailing" (p. 119).

The fundamental incompleteness of all causal stories has coexisted with faith in explanatory reduction because of scientists' confidence that a physical explanation could, in principle, be given of the things that are left unexplained in each particular causal account. For logical consistency, it should be scientifically and philosophically legitimate to invoke things that look like formal or final causes if these could, in principle, be explained by physical and material causes.

The intent of this paper was to defend the use of formal causes (information) and final causes (functions) in evolutionary explanation, but the paper has evolved to address broader questions. Formal causes will be seen as abstractions of material causes and final causes as an efficient way of talking about efficient causes. Form can be grounded in material cause because the matter of evolved beings possesses intricate fine structure that embodies experience of what has worked in the past. Purpose can be grounded in efficient cause because current means are explained by past ends via the recursive physical process we call natural selection. At times during the presentation of formal causes I will mention ends and purposes without yet having justified that language. I ask that these questions be held in abeyance until my discussion of final causes. 


\section{Eggs and chickens}

“Let's think of eggs. They have no legs. Chickens come from eggs But they have legs. The plot thickens: Eggs come from chickens, But have no legs under 'em. What a conundrum!" (Nash 1936)

Consider a causal chain: $A$ causes $B$ causes $C$ causes $D$ causes $E$. Prior things cause posterior things. $C$ is an effect of $A$ and $B$ but a cause of $D$ and $E$. So much is simple. But what happens when things recur? ... $A_{i-1}$ causes $B_{i-1}$ causes $C_{i-1}$ causes $D_{i-1}$ causes $E_{i-1}$ causes $A_{i}$ causes $B_{i}$ causes $C_{i}$ causes $D_{i}$ causes $E_{i}$ causes $A_{i+1}$ causes $B_{i+1}$ causes $C_{i+1}$ causes $D_{i+1}$ causes $E_{i+1} \ldots$ where the recursion continues into the indefinite past and indefinite future. Each type occurs both before and after each other type. A token is either cause or effect of another token-it cannot be both-but cause and effect are inextricably entangled once one attempts to generalize and describe lawful relations among types. Types are both causes and effects of each other (and of themselves). A linear chain was chosen here for simplicity of exposition but similar arguments could be developed for multidimensional webs.

When an amplifier feeds back, what sound is input and what is output? 'Selfevident' distinctions between cause and effect are far from obvious in recursive processes. As one moves back along a chain of physical causation, one encounters things that resemble things to be explained. Eggs produce chickens and chickens produce eggs. Genes are causes of phenotypes and phenotypes causes of which genes replicate (Haig 1992). 
A phenotypic effect $(P)$ may be viewed as both a cause and consequence of a genotypic difference $(G)$ when both are considered as types. A complete causal account of $P_{i}$ (subscripts indicate tokens) would include many prior occurrences of $P$ plus many prior occurrences of $G$ and would resemble a complete causal account of $G i$. If $P_{i-1}$ causes $G_{i}$ causes $P_{i}$ causes $G_{i+1}$, then it is a matter of preference whether $P$ is considered the cause and $G$ the effect or the other way round. A molecular biologist argues from $G$ to $P$ when explaining how gene expression determines phenotype whereas an evolutionary biologist argues from $P$ to $G$ when explaining why a gene has its particular effects. The former mode of explanation is commonly accepted as unproblematic whereas the latter is rejected as teleological and unscientific. But this is no more than a convention of scientific story-telling. Phenotypes are among the efficient causes of genotypes (the central dogma of molecular biology notwithstanding).

Two other points are worth making briefly. First, a recursive non-equilibrium system must be thermodynamically open because a closed system cannot return to an earlier state. Second, evolution requires imperfections in recursion or nothing can change.

\section{Retrorecursion}

"Information can exist only as a material pattern, but the same information can be recorded by a variety of patterns in many different kinds of material. A message is always coded in some medium, but the medium is really not the message." (Williams 1992, p. 10) 
Most eukaryotic genomes harbor retroelements that replicate DNA via RNA intermediates or, what amounts to the same thing, replicate RNA via DNA intermediates. Nothing structural persists in this process. DNA is 'copied' into RNA and then RNA is 'copied' into DNA at a new location in the genome (Finnegan 2012).

An LTR retrotransposon can serve as a paradigm. In its guise as double-stranded genomic DNA, the retrotransposon is transcribed by host-encoded RNA polymerase from an antisense-strand of DNA into a sense-strand of RNA. The resulting RNA can have two functional fates: it can be processed into messenger RNA (mRNA) that is translated by ribosomes into gag and pol proteins; or it can be used as genomic RNA that is packaged with pol and gag proteins as an infective particle. Pol is a remarkable gadget: acting as a reverse transcriptase, pol synthesizes an antisense-strand of DNA complementary to the genomic RNA; acting as an RNAse, pol degrades the RNA template; acting as a DNA polymerase, pol synthesizes a sense-strand of DNA from the antisense-strand; and acting as an integrase, pol inserts the double-stranded DNA into a new site in 'host' DNA (Finnegan 2012). A sense-strand of RNA can be used as a template to make proteins (translation) or antisense DNA (transmission) but the same copy cannot perform both functions.

Retrotransposons trace their origins back before the beginning of cellular life but an active retrotransposon cannot reside long at any one place in the genome. At each location its DNA is inserted, natural selection favors mutations that inactivate and degrade retroelement functions because retrotransposition is costly to organismal fitness. Nevertheless retrotransposition persists because reverse-transcribed DNA 
inserts at new sites faster than mutations degrade source DNA. Mutations that enhance transposition disperse to new sites while mutations that reduce transposition accumulate at old sites. An active element must stay one jump ahead of inactivating mutations. It is a restless wanderer, leaving crumbling genomic footprints at each step along the way (Haig 2012a, 2013).

Retrotransposition involves changes in substance and material form. Consider a nine-nucleotide segment of gag. 5'-CGCACCCAT-3' (antisense DNA) is transcribed into 5'-AUGGGUGCG-3' (RNA) which can be translated as methione-glycine-alanine (peptide) or reverse transcribed as 5'-CGCACCCAT-3' (antisense DNA). The latter is then used to synthesize 5'-ATGGGTGCG-3' (sense DNA). Sense and antisense DNA differ, not only in the use of complementary bases, but also because complementary bases occur in reverse order relative to the sugar-phosphate backbone because of antiparallel pairing. Sense DNA and RNA differ in the substitution of thymine (T) for uracil (U) and in the use of deoxyribose rather than ribose in the backbone. RNA and peptide are chemically chalk and cheese.

Many things within cells are made of DNA, RNA, or protein. Many RNAs are transcribed and many proteins translated. What allows us to pick out a retrotransposon as a nameable entity from these other components and activities? What thing can be held responsible? The retrotransposon is distinguished from other cellular components because it possesses distinct criteria for evolutionary success. Sense DNA, antisense DNA, sense RNA, and peptide are linked by complex causal dependence but are structurally unrelated. Each can be considered to represent the others as material avatars 
of an immaterial gene. ${ }^{1}$ The 'information' that is the retrotransposon must repeatedly change substance and location to persist in an unbroken chain of recursive representation. ${ }^{2}$ There is, in principle, a complete causal account that invokes nothing but efficient and material causes, and in which there is recurrence without continuity of any material thing, but one cannot give a meaningful account of a retrotransposon without reference to its telos and eidos. The forms are shadows of shadows. ${ }^{3}$

\section{Formal causes and information}

"If it be true that the essence of life is the accumulation of experience through the generations, then one may perhaps suspect that the key problem of biology, from the physicist's point of view, is how living matter manages to record and perpetuate its experiences." (Delbrück 1949)

Medieval Latin informatio referred to molding or giving form to matter (Capurro and Hjørland, 2003) but Anglo-Norman informacione (13 ${ }^{\text {th }}$ cent.) was a criminal investigation by legal officers. Metaphors of information abound in modern biology. Not everyone who uses them is a fool. There must be meaning behind the metaphors but precisely

${ }^{1}$ Gouyon and Gliddon (1988) wrote "any material support which allows the replication of genetic information will be termed an avatar, which is used in the Hindu religion to refer to the material forms assumed by the god Vishnu."

${ }^{2}$ Representation presents again in different form, but prior forms are present again when forms recur. By this means, a thing represents its self (Hofstadter 2007; Haig 2011).

${ }^{3}$ This is my footnote to Plato. 
what has been difficult to pin down. Delbrück (1971) wrote that "'unmoved mover' perfectly describes DNA; it acts, creates form and development, and is not changed in the process." Biological information, whatever that may be, performs an explanatory role similar to Aristotle's eidos (Grene 1972).

An evolutionary distinction between information and objects in which information resides has often been made. It appears in contrasts between replicators and vehicles (Dawkins 1976), information and its avatars (Gliddon and Gouyon 1989), codical and material domains (Williams 1992), and informational and material genes (Haig 1997, 2012). In the latter formulation, material genes were physical objects but informational genes were the abstract sequences of which material genes were temporary vehicles. Material genes were identified with gene tokens and informational genes with gene types, but this is not quite right if 'type' is interpreted as a material kind. Sense DNA, antisense DNA, RNA and protein all represent an informational gene but are not molecules of one kind. Continuity resides in the recursive representation of immortal pattern by ephemeral avatars.

Shannon information quantifies the reduction of uncertainty for a receiver observing a message relative to other messages it could have been. The larger the set of possible messages the greater the reduction in uncertainty. Perhaps a better formulation, would be to say that information measures the reduction of uncertainty of an interpreter observing one thing rather than other things it could have been. The interpreter uses the observation to select an interpretation from a set that matches possible interpretations to possible observations. In this formulation, the interpreter can observe the environment, 
or things intended to be hidden, but a message corresponds to the special case of information sent with intent.

A human genome contains 3.2 gigabases $(\mathrm{Gb})$ with up to two bits of information per base (a choice from four alternatives). Therefore, a human genome contains 6.4 gigabits of information relative to the set of all possible $3.2 \mathrm{~Gb}$ strings. This is the reduction in uncertainty provided by a particular sequence for an interpreter who had no prior knowledge other than the length of the sequence. Every $3.2 \mathrm{~Gb}$ string contains the same information but most strings are meaningless (Winnie 2000; Moffatt 2011). Only an infinitesimal subset of the Vast library of $3.2 \mathrm{~Gb}$ sequences contains genomes that have ever existed (Dennett 1995). Other measures of Shannon information might compare the sequence to the set of all extant human genomes or to the set of all past genomes. The amount of Shannon information depends on the background knowledge of the receiver. Information and meaning are distinct. A DNA sequence contains information that acquires meaning when the sequence is interrogated for answers to particular questions. One might use it to determine the amino acid sequence of an otherwise unknown protein or to search for the cause of genetic disease in a patient. Genomes contain clues about evolutionary history if we can only read the hints. If an individual carries the Benin sickle-cell $S$ haplotype, then we can infer that he or she had recent ancestors who lived in West Africa and survived malaria. Other inferences can be made by comparing sequences. We compare DNA documents to reconstruct phylogenetic trees, to date times of divergence, to infer ancestral population size, or to locate regions of positive selection. 
Information has meaning for an interpreter when it is used to achieve an end. The proximate end of the interpretative process is an interpretation of the information. Interpretation of one thing as another differs from simple change of one thing into another because of its end. An interpretation is intended for use but an uninterpreted change simply occurs. ${ }^{4}$

Meaning is a property of the interpretation not of the information because the same information can mean different things to different interpreters. A sender may intend a particular interpretation, and have constructed a message accordingly, but how the message is interpreted is determined by the interpreter. An interpreter may observe more, or less, than was intended by the sender.

Meaning is extracted from a DNA sequence, represented in the output of an automatic sequencer, when a technician reads $\mathrm{T}$ rather than $\mathrm{A}$ and infers that a fetus will express hemoglobin S. The technician's end is clinical diagnosis. Meaning is extracted from the same DNA sequence, represented as an RNA message, when a ribosome

${ }^{4}$ My account of meaning can be viewed as parallel to Peirce's (1877) account of belief. His trinity of belief, desire, and action - "our beliefs guide our desires and shape our actions" - can be loosely translated as my triad of meaning, end, and interpretation. For Peirce, beliefs were habits of mind that guided action: "Belief does not make us act at once, but puts us into such a condition that we shall behave in some certain way, when the occasion arises." Represented in other words, beliefs were latent information whose meaning was expressed in conditional action to achieve a motivated end. 
incorporates valine rather than glutamate into a $\beta$-globin chain. The ribosome's end is protein synthesis. Selectively-neutral single-nucleotide polymorphisms have meaning for a geneticist who uses them to isolate a disease-causing gene but no meaning for the organisms from which they come. No meaning is extracted when DNA is eaten by a bacterium. The use of something as an object (throwing a stone), rather than as a representation (reading a stone tablet), does not count as use of information.

A pause is in order. A thing contains information when it differs from something else it could have been. Two things contain mutual information if an observer can learn about one by observing the other. This is a symmetric relation. An effect represents its cause when observation of the effect allows inference about the cause. This is an asymmetric relation: $X_{i}$ represents $Y_{i}$ to the extent that $Y_{i}$ is causally responsible for their mutual information. A thing has meaning for an interpreter when its 'difference from something else' is used by the interpreter to achieve an end. An interpretation is a representation of the information used by the interpreter.

An interpretation can be the text interpreted by another interpreter. Interpretation is recursive when interpretations return to prior forms. $X$ and $Y$, considered as types, reciprocally represent each other if the token $X_{i}$ represents $Y_{i}$ represents $X_{i-1}$ represents $Y_{i-1}$. Replication is reliable, high-fidelity, recursion of interpretation. (The game of 'Chinese whispers' shows what happens when representation is unreliable.) The text of a replicator is an interpretation of itself.

Living things are replete with reliable reciprocal representation. Each strand of the double helix represents the other. An mRNA represents the DNA from which it is 
transcribed and the DNA represents the mRNA. A protein represents the mRNA from which it is translated and the mRNA represents the protein. DNA represents protein and protein represents DNA. Extended phenotypes represent genotypes and genotypes represent extended phenotypes (Dawkins 1982; Laland et al. 2013). All represent what has worked in past environments. Natural selection creates complex causal dependence between past environments and patterns and processes within cells.

Life is made meaningful by a multitude of mindless interpreters reinterpreting the molecular metaphors of other mindless interpreters. RNA polymerases transcribe DNA as RNA. tRNAs interpret codons as places to deposit amino acids. Ribosomes translate RNA sentences into protein poetry. Higher-level interpreters depend on the activity of myriads of lower-level interpreters. Islet cells integrate blood glucose and other inputs to regulate insulin. Fat cells, muscle cells, and liver cells interpret insulin for diverse ends. Neurons respond to signals from muscles and muscles to signals from neurons. Brains comprehend social relations. You read this sentence. Organisms are selfconstructed interpreters of genetic texts in environmental context.

The environment chooses phenotypes and thereby chooses genes that represent its choices and embody information about the environment's criteria of choice. Observation of these choices would reduce the uncertainty of an omniscient observer about which genes will be transmitted to future generations. The choices of the environment are unintended but actions that are repeated because of their effects are thereby intended. The choices of the environment are not themselves messages, but genes that represent these choices are copied and passed as messages from one generation to the next 
(Bergstrom and Rosvall 2011). Organisms and their lower-level parts are senders and interpreters of these texts.

\section{Difference demystified.}

"A difference is a very peculiar and obscure concept. It is certainly not a thing or an event." (Bateson 1972, pp. 451-2)

A soldier fires at Marius but Éponine blocks the shot with her body saving Marius' life. The difference between the soldier firing or not firing makes no difference as to whether Marius survives but makes a difference as to whether Éponine survives. Éponine's choice, the difference between lunging forward or holding back, makes the difference between Marius' death or survival. The soldier's shot is responsible for Éponine's death, and Éponine's sacrifice is responsible for Marius' survival, but the soldier's shot is not responsible for Marius' survival. Responsibility is not transitive.

Things or events do not make a difference. Differences between things or events make a difference. One cannot decide whether something is responsible for an outcome without answering the question, compared to what? A choice is an act that could have been otherwise and may make a difference.

A physician gives morphine to a patient dying of cancer. The difference between a fatal and non-fatal dose does not make a difference between the patient dying or not dying, but does make a difference between the patient dying a painful or non-painful 
death. If I tell you the dose of morphine I do not provide any information about whether the patient lives or dies but provide information about the nature of the death. ${ }^{5}$

Bateson (1972) defined the unit of information as a "difference which makes a difference"whereas many philosophers define causes to be makers of difference (Lewis 2000, Sartorio 2005). There is indeed a close connection between concepts of cause and information: a cause can be considered a difference that makes (or explains) a difference. The former difference is the cause and the latter its effect. ${ }^{6}$ Observation of either difference contains information about the other. This information is potentially about the relation between cause and effect but $u s e$ of the information requires an interpreter that has either been designed or evolved for that end.

Consider again the nine-nucleotide segment of gag antisense DNA embedded within a much longer sequence. When this sequence is interpreted by an RNA polymerase every DNA base makes a difference in the resulting RNA sequence: 5'-CGCACCCAT-3' is transcribed as 5'-AUGGGUGCG-3'.7 The RNA polymerase receives its instructions

${ }^{5}$ The physician takes the role of the first assassin and cancer the role of the backup assassin in scenarios of causal preemption (e.g., Hitchcock 2007). If the patient does not die from an overdose, then the patient dies from cancer.

6 "To the common sense of mankind it is the property of a cause, qua cause, that it might have been different and have had different effects" (Fisher 1934, p. 106).

${ }^{7}$ I remind readers that $\mathrm{T}$ at the $3^{\prime}$ end of the DNA segment corresponds to A at the $5^{\prime}$ end of the RNA segment because of antiparallel synthesis. 
from a DNA sequence in which every base conveys actionable information: A means 'choose U', C means 'choose G', G means 'choose C', and T means 'choose A.' Once transcription is initiated, and until it terminates, RNA polymerase always interprets A, C, G, or T as U, G, C, or A regardless of the context of surrounding bases. Every change in the DNA base sequence would cause a change in the RNA sequence (given a wellfunctioning RNA polymerase).

Ribosomes translate 5'-AUGGGUGCG-3' as methione-glycine-alanine. They are more sophisticated interpreters than RNA polymerases because the meaning of bases for ribosomes is determined by context. The AUG triplet communicates crucial information. It is the symbol 'start here with methionine' that initiates most polypeptides and sets the reading frame for translation of the rest of the message in triplets. AUG in the body of an mRNA (when in the correct reading frame) simply means 'choose methionine'. The two meanings are distinguished by context.

G appears five times in the nine RNA bases. The G in AUG is essential for the meaning 'choose methionine' because any other base in that position would result in a different amino acid added to the polypeptide. The two Gs in GGU taken together mean 'choose glycine' (the ribosome also interprets GGC, GGA and GGG as 'choose glycine'). The first G in GCG means 'choose alanine' in the context of $C$ in the second position, any other base in the first position would be interpreted as a different amino acid, but the G in the third position of GCG does not make a difference and could be replaced by any other base without a change from alanine. However, a deletion of the third base (a 
difference between nobase and somebase) would cause a frameshift and a change in the interpretation of the rest of the message.

RNA polymerases and ribosomes choose from ensembles. When an RNA polymerase transcribes $G$, it picks out a $C$ from a cytoplasmic mixture of $U, C, A$, and $G$. Similarly, when a ribosome translates AUG, it selects a tRNA charged with methionine from a mixture of tRNAs charged with all twenty amino acids. Methionine is the bon mot the ribosome seeks to capture the meaning of AUG. AUG is present in this position in the RNA message because it has competed, and will compete, with alternatives such as ACG or UUG that have different denotations for the ribosome and connotations for the organism. Natural selection among variant texts chooses those that are useful and discards the rest. Thereby the macrolevel of ecology and social interactions informs the microlevel of molecules.

Some changes to an RNA message change the amino acid added to the growing polypeptide - these are differences that make a difference in the translated proteinwhereas other changes are synonymous and make no difference in translation. The choice of a particular amino acid at a particular location in a protein may have no effect on protein function, in which case different codons are meaningful for the ribosome but meaningless for the organism. The difference in the mRNA (and the DNA from which the message was transcribed) causes a difference in the protein but does not cause a difference in fitness. The choice of amino acid by the ribosome is purposive but the choice of nature is random. 
A choice is a difference that makes a difference. It is a branch point at which a traveller could have gone by different paths but, once one path is chosen, the path taken informs an observer of the traveller's choice. Information about what befalls on a path would be useful in making a choice if the traveller ever came that way again. If travellers copy their choices for later reference, and death awaits on one path but safety on another, then the choices that take the wrong path never return to the fork in the road but the choices that take the right path return to make the same 'wise' choice again. In a perilous maze, the records of surviving travellers provide a safe guide for finding a way.

Choices are degrees of freedom and the meanings of information are the choices it guides. Information is useful if, and only if, it helps to change the future for the better. By tortuous paths, we have come to view choice as synonymous with cause and information as a potential guide to choice. Given a textual record of recurring choices, Darwin's demon (Pittendrigh 1961) culls the bad choices and retains the good. Wellinformed choice is purposive difference making.

\section{Final causes and functions}

\footnotetext{
"It follows that there are several causes of the same thing ... And things can be causes of one another, e.g. exercise of good condition, and the latter of exercise; not, however, in the same way, but the one as end and the other as source of movement." (Aristotle 1984; Metaphysics, p. 1600)
}

Teleological language in biology appears in a heterogeneous class of explanations united by the loose property that a thing's existence is explained by an end (telos) that the thing 
makes possible. A beaver grows sharp incisors to cut down trees to build a lodge to provide shelter from the storm. Dental development has the goal of sharp incisors with the function of cutting down trees for the sake of building a lodge for the purpose of shelter, all for the good of a beaver. "In order to gain access to buried stretches of DNA inside nucleosomes, a chromatin remodeling ATPase is required to unwrap the nucleosomal DNA" (Mellor 2005) is no less teleological than "the hairs about the eye-lids are for the safeguard of the sight" (Bacon 1605/1885, p. 120).

A final cause explains something by its effects. The thing exists for the sake of an end. In the absence of conscious intent, such explanations have been rejected because explanandum precedes explanans. However, this argument loses force for products of natural selection because ends $i$ can be causes of means $s_{i+1}$ without backward causation. A thing exists today because similar things in the past had effects that enhanced survival and reproduction. The thing expresses similar effects in the present because its effects are heritable. Therefore the thing considered as a type exists because of its effects.

Ends can be means to other ends. Ayala (1970) distinguished proximate ends, the functions or end-states a feature serves, from the ultimate goal of reproductive success. Most biological research addresses the end-directedness of adaptations to achieve proximate ends without explicit reference to ultimate goals. The proximate ends of the mindless interpreters described in previous sections are interpretations of information from the environment or sent as genetic texts. The purposeful behavior of these interpreters can be explained as the outcome of selective processes that incorporated 
information about what worked in past environments into the fine structure of information-carrying molecules.

Selection means choosing from a set of alternatives. If there is no alternative, there can be no choice. In Darwin's metaphor of natural selection, the environment 'chooses' via differential survival and reproduction. In Haig's (2012) formalism of this process for genetic replicators, the environment chooses among effects of genes and thereby chooses among genes. An effect is a difference a gene makes relative to some alternative. It is not a property of an individual gene but rather a relation between alternatives. The selected gene is a difference that made a difference. In this formalism, phenotype (synonymous with a gene's effects) is defined as all things that differ between the alternatives, whereas environment is defined as all things shared by the alternatives. By these definitions, what is a phenotype in one comparison may be environment in a different comparison. Natural selection will tend to convert phenotype into environment because environment is that for which there is no reasonable alternative. ${ }^{8}$

Choices of the environment reduce uncertainty about which genes will leave descendants and the selected genes thereby convey information about these choices to ribosomes and other mindless interpreters in subsequent generations. If the choices of the environment are non-random, then the genes embody usable information about the environment's criteria of choice and guide effective choices of organisms.

\footnotetext{
${ }^{8}$ Deleterious mutations are alternatives that are eliminated as soon as they occur. They have a phenotype but are unreasonable choices.
} 
A gene is 'responsible' for its effects. Changes of allele frequency extract average additive effects on fitness from a matrix of non-additive interactions (Fisher 1941). Whatever effects of an allele contribute to a positive average effect on fitness can be considered final causes of the allele's persistence. A gene's function can be defined as those of its effects that have contributed positively to its spread and present frequency. All other effects, negative or neutral, are side-effects without function. If an effect contributes to a gene's success - by any route, no matter how devious - then the gene exists for the sake of that end and the end exists for the good of the gene (Haig and Trivers 1995; Haig 2012).

In the struggle for existence in a world of finite resources, one variant's success comes at the expense of alternatives. The causes of death of individuals without an allele contribute to an allele's success, just as much as the causes of survival of individuals with the allele. ${ }^{9}$ An allele must make a difference in many lives if it is to spread by natural selection, from a single copy arising by mutation in a germ cell to fixation in a population of many individuals. No one event can be singled out as the cause of adaptation but many similar events, distributed through space and time, result in adaptive change. Natural selection is not an efficient cause but a statistical summary of many efficient causes.

${ }^{9}$ The less-appealing traits of the suitors rejected by my mother in favor of my father comprise part of a complete causal account of how I happen to be writing this essay. 
One must consider not only allelic substitutions but also failures of substitution. All adaptations will degrade over time unless mutations that impair the evolved function are weeded out. Each new mutation creates an allelic difference that is subject to selection on the basis of its average effect on fitness. If the mutation is eliminated by a choice of nature, then the difference of phenotypic effect exists for the good of the allele chosen. Many phenotypically interchangeable, but genetically distinct, loss-of-function mutations can be grouped together into a single allelic difference. In this way, a genetic function, determined by interactions between multiple sites within a coding sequence, can be considered for the good of the evolutionary gene.

Consider the substitution of thymine for adenine in the middle base of the sixth codon of the human $\beta$-globin gene. This difference causes a replacement of glutamate by valine at the sixth amino acid position of the $\beta$-globin polypeptide. The resulting protein, hemoglobin $S$, is responsible for sickle-cell disease when homozygous and resistance to malaria when heterozygous. The alternative allele with valine at position 6 is known as hemoglobin A. ${ }^{10}$ With respect to the allelic difference between $A$ and $S$, the function of $S$ is containment of malarial infection in a genotypic environment that includes an $A$ allele.

${ }^{10}$ This sentence deliberately confuses gene and protein. Proteins and genes often share the same name (metonymy). Sometimes a gene is named for its protein and sometimes a protein for its gene. By convention, the gene and its mRNA are italicized but not its protein. In speech, the denotation of a name often encompasses gene, mRNA, and protein. 
A deleterious side-effect of $S$ is life-threatening anemia in a genotypic environment that includes another $S$ allele (see discussion in Haig 2012).

The sickle-cell mutation has been presented as an exemplar of a 'selfish nucleotide' and used to dispute the identification of 'evolutionary genes' with DNA (Griffiths and Neumann-Held 1999). The reductio ad absurdum fails because evolutionary genes have been defined as stretches of DNA rarely disrupted by recombination (Williams 1966, Dawkins 1976) and sufficiently short to maintain linkage disequilibrium (Haig 2012). Non-random associations of variable nucleotides, some of which may be functional, extend for hundreds of kilobases to either side of the 'selfish thymine' (Hanchard et al. 2007). As recombination between sites lessens, and as the strength of epistatic selection increases, a point is reached at which different sites can no longer be considered as belonging to different evolutionary genes (cf. Neher et al. 2013). For sites sufficiently close together, non-additive interactions on the axis of expression contribute to an additive effect on the axis of transmission (Neher and Shraiman 2009; Haig 2011a).

Any complex organismal adaptation will involve many allelic substitutions at multiple loci. For ancient adaptations, most substitutions will have occurred in the deep past, in organisms and environments very different from those of the present. In the process, some genes may have been transformed beyond recognition. While each substitution could be considered for the good of that gene at that time, the adaptation serves proximate ends today. For what entity are these ends a good? A standard answer is that complex adaptations are for the good of the organism. A gene-selectionist could 
counter that a complex adaptation is for the good of each and every gene whose loss of function by mutation results in loss of the adaptation (Haig 2012).

\section{Darwin's demon}

“The literature written by [Darwin's] Demon is no more deducible from a complete command of the nucleotide language, let alone physical law, than the works of Shakespeare or Alfred North Whitehead are deducible from a complete command of the English language." (Pittendrigh 1993)

Maxwell imagined a demon that performed work by choosing which molecules to allow through a partition, thereby selecting ordered subsets from a disordered ensemble. Chickens can unscramble eggs by eating them (Gregory 1981, p. 137).

A rocket is a rigid tube, open at one end, that converts the disordered molecular motion of combustion into coherent motion of the tube. Roughly speaking, the closed end of the tube selects molecular momentum orthogonal to its surface and imparts that momentum to the rocket while the open end discards momentum in the opposite direction. The rocket engine is the selective environment that chooses an ordered subset of moving particles from a disordered set as the entropy of the working material increases. A piston selects molecular momentum orthogonal to the one moveable wall of a cylinder and thereby does work while discarding unworkable energy into a heat sink (Atkins 1994, p. 83). Organisms are elaborate self-assembling engines that acquire or synthesize their own fuel and dump entropic excrement. They are the selective environment by which food is converted to work. 
Subset selection is a semantic engine. Consider a set subject to a procedure by which some are 'chosen' and others 'rejected'. Choice is random if membership of the selected subset is determined by criteria independent of intrinsic properties of things chosen (for example, if no attribute has a periodicity of five but every fifth entity is selected). The disjunction of selected and discarded subsets contains no information about the criteria of choice when choice is random. However, the disjunction contains information about the criteria of choice when choice discriminates among members of a set on the basis of one or more of their intrinsic properties (a reasoned choice). The selected and discarded subsets are biased samples of the whole. One might say that one is adapted, and the other maladapted, to the selective environment.

Wind winnows wheat from chaff by the criterion of weight to cross-sectional area. A bird picks berries from a bush on the basis of palatability and the bird's criteria of choice are reflected in differences between eaten and uneaten berries. A man chooses a wife and we can infer something about his preferences by comparing his spouse to others who were available but passed over. His choice is restricted to members of a comparison set constrained by the comparison sets and preferences of potential partners. You can't always get what you want.

Natural selection, it has been said, differs from subset selection because "offspring are not subsets of parents but new entities" (Price 1995). But the genes of the next generation are a subset of the genes of the last. Therefore, natural selection can also be inscribed under the rubric of subset selection if focus shifts from vehicles to replicators, from interpretations to texts. Natural subset selection is indirect. The environment 
selects a subset of phenotypes to be parents and thereby selects a subset of genes to be transmitted.

Selection from a selected subset retains information from past choices, imperfectly. Retention is imperfect because information is dissipated by random culling, by random mutation of past reasoned choices, and by changes in criteria of choice. In the absence of replication, recursive selection reduces the size of the comparison set at each round of choice. Replication creates redundancy and thus increases the probability that information from past choices will be retained despite dissipative forces.

Mutations are random guesses in the neighborhood of previous choices. Mutation degrades semantic information about past choices but adds entropy for future reasoned choice. For the right balance of mutation and selection, recursive selection of mutable replicators results in accretion of semantic information and refinement of fit to criteria of choice.

\section{Mendel's demon}

“Why all this silly rigmarole of sex? Why this gavotte of chromosomes? Why all these useless males, this striving and wasteful bloodshed?" (Hamilton 1975)

Clonal reproduction replicates entire genotypes that are judged repeatedly in the court of environmental opinion. Each asexual genotype is a single 'evolutionary gene' responsible for its own average effects after repeated retesting. The difference between genotypes that differ at a single site can be attributed to that site but responsibility 
cannot be attributed to individual sites when genotypes differ at multiple sites. Segments of particular value must share credit with segments that do not pull their weight and are hidden from blame. All must share in communal praise and collective guilt.

Sexual genotypes, by contrast, are ephemeral. Judgment of each individual genotype is unique and unrepeated but smaller segments are tested repeatedly against different backgrounds and can be held responsible for their average effects. Sexual genotypes are pastiche, cobbled together from parts of two parental genomes, four grandparental genomes, eight great-grandparental genomes (you get the idea), in a process that mindlessly breaks up effective combinations for the chance of something better. Every one of these genomes has been tested by the environment and passed. The sexual disassembly and reassembly of genotypes allows attribution of responsibility to parts.

Mendel's demon (Ridley 2001) is a randomizing agent that shuffles the genetic deck and deals out fresh hands in each round. It can be a mischievous imp that impedes the work of Darwin's demon by breaking-up favorable combinations or a helpful sprite that rescues parts of promise from bad company. As the genome is diced into smaller pieces, the range of effects for which each non-recombining segment can be held responsible diminishes (Godfrey-Smith 2009, p. 145; Okasha 2012) but each segment is more readily held responsible for its causal effects. Darwin's and Mendel's demons, working together, create teams of champions rather than champion teams (Haig 1997). 


\section{Peirce's demon}

“Experiment ... is an uncommunicative informant. It never expiates: it only answers 'yes' or 'no' ... It is the student of natural history to whom nature opens the treasury of her confidence, while she treats the cross examining experimentalist with the reserve he merits." (Peirce 1905)

Peirce (1905) compared an experimental scientist with men whose education had largely been learned from books: "he and they are as oil and water, and though they be shaken up together, it is remarkable how quickly they will go their several mental ways, without having gained more than a faint flavor from the association." His vivid use of metaphor belied his admonition "that no study can become scientific ... until it provides itself with a suitable technical nomenclature, whose every term has a single definite meaning universally accepted among students of the subject, and whose vocables have no such sweetness or charms as might tempt loose writers to abuse them." He contrasted the poverty of the experimentalist's "meagre jews-harp of experiment" to the richness of the naturalist's "glorious organ of observation." Despite such a seemingly invidious comparison, the rational purport of belief was to be found solely in answers to repeated experiments and their consequences for future conduct:- "if one can define accurately all the conceivable experimental phenomena which the affirmation or denial of a concept could imply, one will have therein a complete definition of the concept, and there is absolutely nothing more in it." Right conduct is choice guided by experience.

Experiments are choices offered to nature for the resolution of doubt. They provide terse inarticulate answers to narrowly defined questions. These answers are informative 
when they reduce the experimentalist's uncertainty about the state of the world. The belief they engender has meaning when used to guide conduct. By this means, "thought, controlled by a rational experimental logic, tends to the fixation of certain opinions" that are not arbitrary but predetermined by nature (Peirce 1905).

The experimental method (Peirce's demon) and natural selection (Darwin's demon) are resolvers of difference in which choices of nature inform adaptive behavior via the accumulation of useful information. Practice perfects performance by trial and choice. A controlled experiment varies one thing while holding other things constant (ceteris paribus) to determine the difference for which that thing can be held responsible. But experiments must be replicated to average out residual, uncontrolled, variation. Sexual recombination achieves a similar statistical control by repeated retesting of allelic differences on different genetic backgrounds. The average effects of allelic differences reduce the complexity of biological interactions to simple binary choices. The success of the experimental method and of sexual organisms suggests that short-sighted choice among recombinable units often outperforms reasoned judgment of integrated wholes.

The histories of causal and legal concepts are closely intertwined. The function of a trial is to determine whether a defendant is responsible for a crime. Many circumstances and opinions are weighed in the balance but the judgment is binary, guilty or not guilty. The earliest known meanings of try are to sift or pick out, to separate one thing from another, especially the good from the bad, and to choose or select. A trial was the determination of a difference, between guilt or innocence, by tribunal, battle, or ordeal. 
Natural selection is a recursive process of trial and judgment by which good causes are rewarded and relative truths learnt.

\section{Gene-selectionism and developmental systems theory}

"... a thing exists as a natural end if it is cause and effect of itself." (Kant 2000, p. 243)

Phenotype interprets genotype in environmental context. Why should genes be singled out as possessors of purposes and as self-interested beneficiaries of adaptation? Genes belong among the material causes of development, and gene expression among its efficient causes, but ontogeny proceeds via complex interactions between genes and environment. From the perspective of developmental systems theory, the causal matrix recreates itself, recursively, without a privileged role for genes (Oyama 2000).

Genes interact with each other and the environment to create phenotypes that causally influence which individuals leave descendants. But, when the environment chooses which allele increases in frequency, the choice is based on the average effect of a difference (Fisher 1941). In Lewontin's (2000) terminology, the allelic effects are causes of difference but the interactions are causes of state. ${ }^{11}$ The prosaic selection of differences creates poetic changes of state (Haig 2012).

Gene selectionism is concerned with how information gets into the genome via natural selection and what can be held responsible for the appearance of purpose in

${ }^{11}$ Lewontin (2000) reprises his earlier distinction between the analysis of variance and analysis of causes (Lewontin 1974). 
nature. By contrast, developmental systems theory is concerned with understanding ontogenetic mechanisms. One might say that gene selectionism addresses the writing, and developmental systems theory the reading, of a text. From this perspective, the frameworks are complementary rather than in conflict. Any text of lasting value is read, and judged, repeatedly as it is revised.

Two domains of explanation are in play that have been characterized as a vertical axis of transmission and a horizontal axis of development (Bergstrom and Rosvall 2011). One concerns the inheritance of genetic information between generations and the other the expression of genetic material within generations. Teleological concepts appear in both domains. On the axis of transmission, final causes appear as adaptations that serve the ultimate end of fitness. On the axis of expression, final causes appear as end-states of developmental processes and as the proximate ends of goal-directed behaviors. Explanations in the two domains have different flavors because mapping from gene to gene copy in the course of transmission is straightforward but from genotype to phenotype in the course of development is devilishly difficult.

The conceptual separation of axes of transmission and development is related to Shea's (2007) separation of phylogenetic and ontogenetic explanations; to Ayala's (1970) distinction between ultimate goals and proximate ends; to Weismann's (1890) separation of germ plasm and cytoplasm; to the difference between DNA replication and RNA 
transcription; to the divide between text and interpretation and the contrast between mention and use of a lexical item. ${ }^{12}$

Whether conceptual separation of developmental from evolutionary questions is productive or counter-productive is a subject of present polemics. Some maintain the distinction is indispensible (Griffiths 2013) whereas others see it as an impediment to understanding (Laland et al. 2013). Most of those who support the distinction are comfortable with invoking functions as causes (Haig 2013a), whereas many of those who want to do away with it are explicit that "functions are not causes ... the outcome of a behavior cannot determine its occurrence" (Laland et al. 2013a).

Our penchant for dichotomies, distinctions, and oppositions reflects the power of reducing complex questions to binary choices. Many arguments within the philosophy of biology, and between the sciences and humanities, reflect a tension between the reductive simplicity of average effects and the richness of interaction; between the 'meagre trump' of attributing credit to parts and the 'glorious Wurlitzer' of integration of wholes. But, we have more than two options. One can play a duet.

\footnotetext{
${ }^{12}$ Kant (2000, p. 243) can be interpreted as making a related distinction when he describes the twofold sense in which a tree is both cause and effect of itself. A tree generates itself both as a species/genus (transmission) and as an individual (development).
} 


\section{Genomes as texts}

“Are God and Nature then at strife, That Nature lends such evil dreams? So careful of the type she seems, so careless of the single life." (Tennyson 1849)

Genomes resemble historical documents (Williams 1992, p. 6; Pittendrigh 1993).

Thymine rather than adenine, or valine rather than glutamate, has no meaning out of context but a nucleotide sequence of $\beta$-globin, with thymine at position 17, or an amino acid sequence of $\beta$-globin, with valine at position 6 , both have meaning in context, although neither says anything explicit about malaria. Genomes are allusive archives of choice, with unstated meanings without explicit expression or discrete location. They are palimpsests on which new text is written over partially erased older text (Haig and Henikoff 2004). Not all of the text is readable. It contains gobbledegook and epigenetic annotations on what should not be read. Genomic censors strive to shut down the clandestine presses of retrotransposons.

Where does meaning reside in a text? My essay evolved via incremental rewording and extensive rewriting. There was a struggle for existence among ideas for space on the page. There is a lot more I could have said. My meaning resides in the difference between what is said and unsaid. Often a change in one part necessitated changes in other parts to maintain consistency. The essay self-consciously reflects back upon itself with repetition, recurrence, reciprocal reference, and allusive alliteration. Part of its metameaning is that many meanings are distributed throughout the text, never fully explicit, 
to reflect and suggest the organization of meanings within the genome. There is no meaning in a letter, a little in a word, a bit more in a sentence, but much of the intended meaning is implicit, to be understood from the synergistic whole rather than the additive parts. And yet, the text was written letter by letter and word by word by additive increments. On the axis of reading, new meanings can be found, but on the axis of transmission it is only that which is written that counts.

Meaning resides in the interpretation. There are meanings I intend you to find and meanings you find. I wrote to persuade. But you may use my prose to persuade others that I am mistaken. You interpret my essay as you will. Imprecision of language allows charity of interpretation and slaying of straw men. Falsehood can arise from misinformation by an author or misinterpretation by a reader.

The question what genes mean, if what genes do depends on interactions with other genes in environmental context, resembles the question what words mean when all definitions are expressed in other words in semantic context. Modern philosophers confront the 'indeterminacy of translation' when attempting to understand what aition meant to Aristotle and 'indeterminacy of interpretation' when attempting to understand, or deliberately misunderstand, each other's arguments. Modern biologists confront similar indeterminacy in the semantic content of genetic material. Critics of 'information talk' in biology often demand a more rigorous justification of meaning in DNA than they could provide for meaning in language.

An idea is the semantic equivalent of a non-recombining segment of DNA. It is a chunk of meaningful stuff that is transmitted as a parcel. It is a semantic difference that 
makes a difference. Ideas and "pithy quotations" are readily reusable because they are meaningful when taken out of context. Science proceeds via recombination of ideas whereas great works of literature are clonally replicated and interpreted as wholes. In the scientific literature, least publishable units have replaced magisterial tomes in part because shorter texts are more likely to be used and cited. Working biologists mostly read the Origin of Species for virtue or pleasure, because the good bits have been reused again and again, in new associations, in a sesquicentury of scientific endeavor.

There are parallels between the ascription of effects to genes and the assignment of credit to authors. Scientists cite each other more than philosophers, novelists hardly at all. Citations not only provide pointers to additional information but also ascribe credit. All new insights originate in the context of many acknowledged and unacknowledged precursors, but credit is easier to attribute, or harder to deny, for portable ideas than for rearrangements in the tangled web of meanings. Tristram Shandy contains philosophical insight but is rarely cited because discrete ideas are difficult to disentangle from its interwoven fabric.

Scientists care about citation because they want their name to hitchhike with 'their' ideas to feedback for their good. But to be worthy of credit one must be unambiguous. Otherwise one could claim credit for interpretations that prove prescient but shift blame for interpretations that fail. A scientist is expected to commit to one interpretation but a novelist often leaves a choice for the reader. Indeterminacy of interpretation is a designed feature of novels but a flaw in experimental notebooks and scientific papers. 


\section{Teleodynamics}

\footnotetext{
"In an indeterministic world natural causation has a creative element, and science is interested in locating the original causes of effects of special interest, and not merely in pushing a chain of causation backwards ad infinitum." (Fisher 1934)
}

Consider the fates of zygotes, scions of countless spermatic races to ova. Their lives unfold via interactions among genes, and between genes and environment. Many fall by the wayside, by chance or necessity, and those that reach maturity produce progeny, some a hundredfold, some thirtyfold, some sixtyfold. Sometimes an allelic difference causes one to leave more issue than another. And, lo and behold, the genes of the progeny, and of the progeny's progeny, even unto the third and fourth generation, are a biased sample of the genes of their progenitors. The tale is repeated, with minor variations and mutations, time without end, and verily there is something new under the sun.

This evolutionary parable could be elaborated endlessly with causal explanations of ever finer detail and ever deeper regression into the past. There is a causal story behind each and every mutation, each and every chiasma, each and every choice of a mating partner, each and every union of gametes, each and every catastrophe that did not happen. But this story is untellable because of incomplete information, chaotic dynamics, and computational complexity. And if it could be told, the story would be incomprehensible. One must simplify to tell a tale, giving greater salience to some items and leaving loose ends. 
A pedant could argue that pressure is not an efficient cause and should be expunged from physical explanations - only individual molecular impacts are truly causal - but his argument would be dismissed as obfuscation. For questions at the appropriate scale, pressure provides a perfectly adequate explanation, indeed one that is superior to the unattainable account that describes each and every molecular collision. Darwinian final causes are similarly grounded in efficient causes and are perfectly adequate, indeed indispensable, for certain kinds of biological explanation. A 'selection pressure' summarizes many reproductive outcomes just as the pressure of a gas summarizes many molecular motions. Darwinism, like thermodynamics, is a statistical theory that does not keep track of every detail (Peirce 1877; Fisher 1934).

Much recent semantic work has been done on concepts of Darwinian information (Adami 2002; Adami et al. 2000; Colgate and Ziock 2011; Frank 2009, 2012). The various expositions exhibit phenotypic resemblance, both from shared ancestry and convergence in a common selective environment, although conceptual differences remain. Rather than choose among the differences, because the available space could not do them justice, I will synthesize a subset of select conclusions. Semantic information comes from the environment via subset selection and refers to that environment. It is functional, looking backward to what has worked in the past and forward as a prediction of what will work in the future. Replication is essential for the indefinite persistence of information in the face of dissipative entropic forces. 


\section{Back to the future}

“The word 'cause' is so inextricably bound up with misleading associations as to make its complete extrusion from the philosophical vocabulary desirable." (Russell 1913)

My intent in partial rehabilitation of formal and final causes is not to argue that the four causes provide the best causal taxonomy for current ends, but to recognize that Aristotle's classification was found useful for more than a millennium and must surely have approximated significant categories of understanding. Moreover, if formal and final causes do not exist in their 'bad' metaphysical senses, then the terms and the concepts are available for use in their 'good' post-Darwinian senses of information and adaptive function.

My essay concerns the seduction of narrative, the magic of metaphor, and the rhythm of recursion (Hofstadter 1979; Haig 2011). Meaning is expressed through metaphor by representing one thing by another. Recursive representation allows eidos and telos to be grounded in hyle and kinesis. Choice captures information. The environment, personified as natural selection, chooses ends and thereby chooses means with meanings, because the ends of the past are the means of the present. Meaning requires an interpreter and an end. Darwin's demon supplies both. My text returns repeatedly to etymologies and histories of ideas because logos and eidos evolve by paths parallel to genes, providing fruitful metaphors and philosophical perspective.

Natural selection is both a metaphor and a metaphorical process of recursive representation. It is a meaningless, purposeless, physical algorithm that produces things 
for which meaning and purpose are useful explanatory concepts (Dennett 1995). Among the products of natural selection are rational agents, with beliefs and desires, pursuing conscious goals, exchanging truthful and deceptive information, who can delight in a meaningful life.

"L-d! said my mother, what is all this story about? - A COCK and a BULL said Yorick-And one of the best of its kind I ever heard" (Sterne 1767, finis). 
Acknowledgments: Daniel Dennett, Jeffrey Lipshaw, Eric Schliesser, James Simpson, Kim Sterelny, Wenfei Tong, and Adrian Young contributed to the manuscript. Samir Okasha is to blame but the credit is mine. Thanks to the Arnold Arboretum under snow for inspiration and the Colloquium on the Fundamental Interconnectedness of All Things for special effects. Particular thanks to the many unacknowledged influences without whom it would not have been written in quite the way it was. In memory of David Haig (1932-2012). 
Adami C (2002) What is complexity? Bioessays 24:1085-1094.

Adami C, Ofria C, Collier TC (2000) Evolution of biological complexity. Proc Natl Acad Sci USA 97:4463-4468.

Aristotle (1984) The complete works of Aristotle. Princeton University Press, Princeton. Atkins PW (1994) The second law. W. H. Freeman, New York.

Ayala FJ (1970) Teleological explanations in evolutionary biology. Phil Sci 37:1-15.

Bacon F (1596) Maxims of the law.

Bacon F (1885) The advancement of learning, ed. WA Wright. Clarendon Press, Oxford.

Bateson G (1972) Steps to an ecology of mind. University of Chicago Press, Chicago.

Bergstrom CT, Rosvall M (2011) The transmission sense of information. Biol Phil 26:159176.

Capurro R, Hjørland B (2003) The concept of information. Annu Rev Inform Sci Tech $37: 343-411$.

Colgate SA, Ziock H (2011) A definition of information, the arrow of information, and its relationship to life. Complexity 16:54-62.

Dawkins R (1976) The selfish gene. Oxford University Press, Oxford.

Dawkins R (1982) The extended phenotype. Oxford University Press, Oxford.

Delbrück M (1949) A physicist looks at biology. Trans Connecticut Acad Arts Sci 38:173190.

Delbrück M (1971) Aristotle-totle-totle. In: Monod J, Borek E (eds) Of microbes and life. Columbia University Press, New York, pp 50-55.

Dennett DC (1995) Darwin's dangerous idea. Simon and Schuster: New York. 
Finnegan DJ (2012) Retrotransposons. Curr Biol 22:R432-R437.

Fisher RA (1934) Indeterminism and natural selection. Phil Sci 1:99-117.

Fisher RA (1941) Average excess and average effect of a gene substitution. Ann Eugenics 11:53-63.

Frank SA (2009) Natural selection maximizes Fisher information. J Evol Biol 22:231-244.

Frank SA (2012) Natural selection. III. Selection versus transmission and the levels of selection. J Evol Biol 25:227-243.

Frede M (1980) The original notion of cause. Pages 217-249, In: Schofield M, Burnyeat M, Barnes J (eds) Doubt and dogmatism. Clarendon Press, Oxford.

Gliddon CJ, Gouyon PH (1989) The units of selection. Trends Ecol Evol 4:204-208.

Godfrey-Smith P (2009) Darwinian populations and natural selection. Oxford University Press, Oxford.

Gouyon PH, Gliddon C (1988) The genetics of information and the evolution of avatars. In: de Jong G (ed) Population genetics and evolution. Springer-Verlag, Berlin, pp. 119123.

Gregory RL (1981) Mind in science. Cambridge University Press, Cambridge. Grene M (1972) Aristotle and modern biology. J Hist Ideas 33:395-424.

Griffiths PE (2013) Lehrman's dictum: information and explanation in developmental biology. Devel Psychobiol 55:22-32.

Griffiths PE, Neumann-Held EM (1999) The many faces of the gene. BioScience 49:656662. 
Haig D (1992) Genomic imprinting and the theory of parent-offspring conflict. Semin Devel Biol 3:153-160.

Haig D (1997) The social gene. In: Krebs JR, Davies NB (eds) Behavioural ecology, fourth edition. Blackwell Scientific, Oxford, pp. 284-304.

Haig D (2011) Sympathy with Adam Smith and reflexions on self. J Econ Org Behav 77:4-13.

Haig D (2011a) Does heritability hide in epistasis between linked SNPs? Eur J Hum Genet 19:123.

Haig D (2012) The strategic gene. Biol Phil 27:461-479.

Haig D (2012a) Retroviruses and the placenta. Curr Biol 22:R609-R613.

Haig D (2013) Genomic vagabonds: endogenous retroviruses and placental evolution. Bioessays 35:845-846.

Haig D (2013a) Proximate and ultimate causes: how come? and what for? Biol Phil 28:781-786.

Haig D, Henikoff S (2004) Deciphering the genomic palimpsest. Curr Opin Genet Devel 14:599-602.

Haig D, Trivers R (1995) The evolution of parental imprinting: a review of hypotheses. In: Ohlsson R, Hall K, Ritzen M (eds) Genomic imprinting: causes and consequences. Cambridge University Press, Cambridge, pp. 17-28.

Hamilton WD (1975) Gamblers since life began: barnacles, aphids, elms. Q Rev Biol 50:175-180. 
Hanchard N, Elzein A, Trafford C, Rockett K, Pinder M, et al. (2007) Classical sickle beta-globin haplotypes exhibit a high degree of long-rang haplotype similarity in African and Afro-Caribbean populations. BMC Genet 8:52.

Hitchcock C (2007) Prevention, preemption, and the principle of sufficient reason. Phil Rev 116:495-532.

Hofstadter DR (1979) Gödel, Escher, Bach. Basic Books, New York.

Hofstadter DR (2007) I am a strange loop. Basic Books, New York.

Kant I (2000) Critique of the power of judgment (translated by Guyer P, Matthews E). Cambridge University Press, Cambridge.

Laland KN, Odling-Smee J, Hoppitt W, Uller T (2013) More of how and why: cause and effect in biology revisited. Biol Phil 28:719-745.

Laland KN, Odling-Smee J, Hoppitt W, Uller T (2013a) More of how and why: a response to commentaries. Biol Phil 28:793-810.

Lewis D (2000) Causation as influence. J Phil 97:182-197.

Lewontin RC (1974) The analysis of variance and the analysis of causes. Am J Hum Genet 26:400-411.

Lewontin RC (2000) Foreword. In: Oyama S, The ontogeny of information, second edition. Duke University Press, Durham, NC, pp vii-xv.

Mellor J (2005) The dynamics of chromatin remodeling at promoters. Mol Cell 19:147157.

Moffatt B (2011) Conflations in the causal account of information undermine the parity thesis. Phil Sci 78:284-302. 
Nash O (1936) The bad parents' book of verse. Simon and Schuster, New York.

Neher RA, Shraiman BI (2009) Competition between recombination and epistasis can cause a transition from allele to genotype selection. Proc Natl Acad Sci USA 106:68666871.

Neher RA, Kessinger TA, Shraiman BI (2013) Coalescence and genetic diversity in sexual populations under selection. Proc Natl Acad Sci USA 110:15836-15841.

Okasha S (2012) Social justice, genomic justice and the veil of ignorance: Harsanyi meets Mendel. Econ Phil 28:43-71.

Oyama S (2000) The ontogeny of information. Developmental systems and evolution, second edition. Duke University Press, Durham, NC.

Pearson L (1952) Prophasis and aitia. Trans Proc Am Philol Assoc 83:203-223.

Peirce CS (1877) Illustrations of the logic of science. First paper. - The fixation of belief. Pop Sci Monthly 12:1-15.

Peirce CS (1905) What pragmaticism is. Monist 15:161-181. (title corrected)

Price GR (1995) The nature of selection. J Theor Biol 175:389-396.

Russell B (1913) On the notion of cause. Proc Aristotelian Soc 13:1-26.

Pittendrigh CS (1961) On temporal organization in living systems. Harvey Lectures $56: 93-125$.

Pittendrigh CS (1993) Temporal organization: reflections of a Darwinian clock-watcher. Annu Rev Physiol 55:17-54.

Ridley M (2000) Mendel's demon. Weidenfeld and Nicholson, London. Sartorio C (2005) Causes as difference makers. Phil Stud 123:71-96. 
Shea N (2007) Representation in the genome and in other inheritance systems. Biol Phil 22:313-331.

Sterne L (1767) The life and opinions of Tristram Shandy, gentleman.

Tennyson A (1849) In memoriam. A. H. H.

Weismann A (1890) Prof. Weismann's theory of heredity. Nature 41:317-323.

Williams GC (1966) Adaptation and natural selection. Princeton University Press,

Princeton.

Williams GC (1992) Natural selection. Domains, levels, and challenges. Oxford University Press, Oxford.

Winnie JA (2000) Information and structure in molecular biology: comments on Maynard Smith. Phil Sci 67:517-526. 